\title{
Individuación, ciencias humanas y humanismo en la teoría de G. Simondon*
}

Individuation, Human Sciences and Humanism in the Theory of G. Simondon

Individuação, ciências humanas e humanismo na teoria de G. Simondon

\section{Lina Marcela Gil Congote**}

\author{
Artículo de investigación \\ Revista Colombiana de Educación, N. 72. Primer semestre de 2017, Bogotá, Colombia.
}

Para citar: Gil, L. M. (2017). Individuación, ciencias humanas y humanismo en la teoría de G. Simondon. Revista Colombiana de Educación, (72), 79-98.

Recibido: 29/09/2016

Evaluado: 30/11/2016

* Este artículo hace parte del proyecto de investigación adscrito a la Facultad de Ciencias sociales y humanas de la Universidad de Antioquia "Bases conceptuales de una psicología de la individuación" (FPP, código 2017002).

** Profesora Departamento de Psicología, Universidad de Antioquia, Medellín, Colombia. Miembro del grupo de investigación "El método analítico y sus aplicaciones en las ciencias sociales y humanas", adscrito a la Universidad de Antioquia y la Universidad Eafit. 


\section{Resumen}

El proceso de individuación psíquica y colectiva, propuesto por Simondon, aporta al debate sobre las ciencias humanas y el humanismo, al considerar el devenir del ser en sus múltiples fases. Se elige el concepto de transindividual como enlace entre las ciencias humanas y el humanismo, para sostener que en su obra convergen una axiomática (poder explicativo, científico, racional) y una posición humanista (comprensiva, axiológica) derivada de la anterior. Se dan en este artículo los siguientes pasos: 1) una axiomática para las ciencias humanas: ontogénesis e individuación; 2) una dimensión transindividual: entre axiomática y humanismo; 3) un humanismo "renovado", y 4) un colofón sobre biopolítica e individuación.

\section{Palabras clave}

axiomática, ciencias

humanas, humanismo, individuación transindividual, tecnicidad

\section{Keywords}

axiomatics, human sciences, humanism, individuation, transindividual, technicity

\begin{abstract}
The process of psychic and collective individuation, proposed by Simondon, contributes to the debate on human sciences and humanism, as it considers the development of the being in its multiple phases. The concept of transindividual is chosen as a link between human sciences and humanism, in order to argue that in Simondon's work come together an axiomatics (explanatory, scientific, rational power) and a humanist position (comprehensive, axiological) derived from the previous one. The following steps are developed in this article: 1) an axiomatics for human sciences: ontogenesis and individuation; 2) a transindividual dimension: between axiomatics and humanism; 3) a "renewed" humanism; and 4) a colophon on biopolitics and individuation.
\end{abstract}

Abstract

\section{Resumo}

O processo de individuação psíquica e coletiva, proposto por Simondon, contribui para o debate sobre as ciências humanas e o humanismo ao levar em conta o devir no ser em suas múltiplas fases. Foi elegido o conceito de transindividual como vínculo entre as ciências humanas e o humanismo, para sustentar que em sua obra converge uma axiomática (poder explicativo, cientifico, racional) e uma posição humanista (compreensiva, axiológica) derivada da anterior. Em este artigo estabelecem-se os seguintes passos: 1) uma axiomática para as ciências humanas: ontogénese e individuação; 2) uma dimensão transindividual entre axiomática e humanismo; 3) um humanismo "renovado", e 4) um colofão sobre biopolítica e individuação.

\section{Palavras chave}

axiomática, ciências

humanas, humanismo, individuação, transindividual, tecnicidade 


\section{Introducción}

I a filosofía del siglo xx coincide en la desustancializacion del ser humano, o desencialización del ser del hombre como centro de la historia. Se dirá, entonces, que el ser es temporal, está en devenir, no puede situarse una esencia que de una vez por todas defina lo que le es intrínseco y, por ende, se sugiere la caída del humanismo; al menos, en su versión moderna (Deleuze, 2005; Foucault, 1997; Heidegger, 1996; Rodríguez, 2010; Sloterdijk, 2000). La propuesta del filósofo francés Gilbert Simondon (1924-1989) al retomar el concepto de individuación también critica cualquier forma de sustancialización y se apoya en un paradigma contemporáneo como la física cuántica para tematizar la manera como el ser en sus fases física, biológica, psíquica y colectiva se desdobla en individuo y en medio, con bases, también, en la cibernética, la filosofía de Bergson, la fenomenología de Merleau-Ponty, la ontogénesis de Piaget y la teoría de grupos norteamericana, entre otros referentes que influyen en su pensamiento (cf. Bardin, 2015; Heredia, 2015).

¿Es Simondon un humanista? ¿Un antihumanista? ¿Un posthumanista? Para responder estas preguntas, se tomarán dos vías en su obra: la propuesta de una "axiomática para las ciencias humanas" (Simondon, 2015a) y el concepto explícito de humanismo. La axiomática propuesta allana el camino para tesis deleuzianas ${ }^{1}$ y foucaultianas acordes con posturas posthumanistas (Blanco, 2015; Del Lucchese, 2009; Heredia, 2015; Iliadis, 2013; Rodríguez, 2016); mientras el humanismo descrito, si bien tiene claras pretensiones de superación, pone de presente aspectos modernos, como la reivindicación de la reflexión ética, la libertad y los fines humanos; especialmente, en conceptos como enciclopedismo y ecumenismo, revisitados en su obra desde la perspectiva de la técnica.

En Simondon, el individuo parece sustituir al sujeto y reforzar así la idea de un posthumanismo, claramente opuesto a cualquier vía de sustancialización. Pero categorías como "individuo psicológico", "ser psicológico" e "individuo puro", así como la propia noción de "sujeto", recurrente en su obra, son necesarias para pensar la dimensión psíquica de la individuación y ponen de manifiesto un quien, que se pregunta por

1 Es conocida la influencia de Simondon en Deleuze (1995); desde el debate sobre la formación (Vargas \& Gil, 2015), se encuentra que la diferencia es un efecto necesario, pero sin atender los procesos de individuación que están a la base, se diluye (o, al menos, toma un lugar secundario) lo que Simondon enlaza por la vía de la ontogénesis: diferencia, individualización -identidad como efecto-y, al mismo tiempo, vínculo con otros, resonancia a partir de significaciones compartidas; en otros términos, la importancia de conjugar la tradición, la repetición, lo dado colectivamente, así como el cada uno, el aporte novedoso o singular en tanto individuación en devenir. Esta no acontece por fuera de un entorno y una cultura, ni de unas condiciones previas de existencia que operan como potenciales para ser actualizados en una dimensión transindividual. 
los valores, por el sentido y por la ética, y que reflexiona sobre sus acciones y las orienta a fines -incluso, de progreso-desde criterios de individuación apuntalados en preguntas propias del humanismo. Convergen, entonces, tendencias que no se anulan (axiomática y humanismo), desde una posición que no se deja enmarcar fácilmente dentro de una u otra categoría, como suele ser su obra: filósofo de la técnica, pero con una tesis transversal sobre la ontogénesis, sin la cual resulta difícil comprender el alcance y la novedad de su propuesta. El concepto de transindividual sirve de puente entre ambas perspectivas, tratadas brevemente, para concluir, desde el ámbito de la biopolítica.

\section{Una axiomática para las ciencias humanas: ontogénesis e individuación}

Simondon propone una nueva axiomática para las ciencias humanas, a partir de los conceptos de forma, información y potenciales, gracias a una operación transductiva. Mediante un "pasaje de información", la transducción acontece en un germen estructural (emisor) que actúa en un campo para propagarse o amplificarse; es decir, los potenciales que se encuentran en la materia se organizan como estructura (Simondon, 2015a). "Esta materia viviente está lejos de ser pura indeterminación y pura pasividad; tampoco es aspiración ciega: es vehículo de energía informada" (Simondon, 2007, p. 81).

En su cuestionamiento al hilemorfismo, Simondon sustituye el concepto de forma por el de información, y añade, entre otros, los conceptos de resonancia interna, potencial energético y órdenes de magnitud, en la triada materia-forma-energía. Todo ello le permite sostener que la individuación es un proceso permanente, en el que no se retorna al equilibrio, sino que se produce una metaestabilidad, o disparidad; es decir, una continua resonancia interna, gracias a lo preindividual. El ser, vía la individuación, "se desdobla en individuo y en medio", producto del "encuentro y de la compatibilidad de una singularidad y de las condiciones energéticas y materiales" (Simondon, 2009, p. 113). El individuo no es el origen de la individuación, sino a la inversa: "no es un accidente en relación con una sustancia, sino una condición constitutiva, energética y estructural, que se prolonga en la existencia de los seres constituidos" (p. 115).

Gracias a un proceso de evolución, los individuos incorporan "una axiomática cada vez más rica" (Simondon, 2009, p. 318), que no consiste tanto en un perfeccionamiento, sino en una integración, un acople o ensamble de funciones y estructuras que acumula potenciales para nuevas individuaciones. Se asume que hay un constante movimiento del ser hacia formas que se organizan de acuerdo con la información interna y a la que el medio ofrece, para devenir este o aquel individuo, que es, 
finalmente, el que tiene la capacidad de traducir "potenciales incompatibles entre sí en equilibrios metaestables que pueden ser mantenidos al precio de sucesivas invenciones" (p. 321), en las diversas fases del ser: un átomo, un cristal, un vegetal, un animal, hasta un sujeto pensante, capaz de concretizar objetos técnicos.

Al igual que la técnica, el individuo no es algo dado, previamente. Como lo plantea Barthélémy (2014, p. 73), la reducción que opera en Simondon es, quizá, la "reducción al devenir" - de tipo bergsoniano-, al tomar a los seres como relaciones, y no como sustancias. Por eso, Simondon pone de relieve la diferencia entre individuo y sustancia desde su ontología genética, cuyo eje no es en sí la pregunta por el ser, sino por el cómo llegar a ser, por fuera del denominado - posteriormente, por Foucault (1997)- "prejuicio antropológico". Es una axiomática que no recurre a la esencia ni al relativismo, sino a una "tercera vía": la ontogénesis (Guchet y Hayward, 2012, p. 81).

Según Simondon (2015a) dicha axiomática consiste para las ciencias humanas en encontrar unos "principios explicativos" comunes que operen en cada una de sus tendencias o sus dominios; en especial, en la sociología y la psicología), consideradas los dos polos que están en la base de las nacientes ciencias humanas en el siglo xIx (Guchet y Hayward, 2012). El autor toma como referencia la física y la química que a principios del siglo xx logran -gracias a la teoría electromagnética de la luz, de Maxwelluna "síntesis creadora" en las ciencias de la naturaleza: una físico-química cada vez más acoplada (Simondon, 2015a). Propone el estudio de los conceptos de forma, información y potenciales en sus diferentes expresiones en la historia: desde el "arquetipo platónico", pasando por el hilemorfismo aristotélico, hasta la psicología de la Gestalt, que logra una síntesis o integración de las anteriores. Sin detenerse en estas distinciones -tema de otra investigación- ${ }^{2}$, se dirá que la axiomática propuesta se apoya en una física que solo toma lo indeterminado y lo determinado como casos puros; entre ambas, propone una "teoría del tiempo transductivo o teoría de las fases del ser" (Simondon, 2009, p. 212), que logre, desde las ciencias humanas, superar la división entre el individuo, visto como átomo, "mónada" o unidad mínima, y el grupo búsqueda de una totalidad, o "universo social" (Simondon, 2015a, p. 485).

2 En sus textos Fundamentos de la psicología contemporánea (1956), Iniciación a la psicología moderna (1965-1966) y La sensibilidad (1966-1967), sostiene que la psicología necesita una nueva teoría de la individuación. En la intención de superar el sociologismo y el psicologismo, propone una "teoría triódica del sujeto" en la que lleva los conceptos centrales de su obra como energía, información, modulación y metaestabilidad al campo de los procesos psíquicos; en especial, la sensación, la percepción, la motivación y el aprendizaje. Es un tema poco investigado de su propuesta y abre horizontes de comprensión para esta disciplina desde un recorrido por sus antecedentes históricos y epistemológicos. Estos textos fueron compilados en 2015b (PUF), bajo el título Sur la Psychologie. 
En la época del autor, la tendencia a privilegiar la estructura favorece que cada disciplina tome su objeto aisladamente y quede en un segundo plano la relación. Cuestiona tanto la macrosociología como la microsociología de su época: la primera, porque no considera la energética humana ni la dimensión afectivo-emotiva; también, por considerar la sociedad desde la homeostasis, y por dejar por fuera de su análisis las técnicas, o hacerlo desde un enfoque que no comparte-como se verá en el apartado sobre el humanismo-. De la segunda (la microsociología), cuestiona el énfasis en la comunicación intersubjetiva (cf. Heredia, 2015, p. 461). Insiste en tomar lo psicológico y lo colectivo como fases del ser, contemporáneas y complementarias, y no como realidades o estructuras separadas ${ }^{3}$.

El referente de unidad que ofrece para las ciencias humanas pretende cuestionar las abstracciones que hasta ese entonces se han tomado como tema de discusión (interior para la psicología, exterior para la sociología, por ejemplo). No obstante, Simondon no busca "imponer un formalismo común a estas ciencias", sino proponer como fundamento o campo una "filosofía de la realidad humana concreta"; esto es, de la individuación, fuente de invención de normas para la sociedad, más que de criterios de normalidad frente a la patología (Guchet, 2012, p. 78).

La axiomática es una forma de expresar la organización que genera la vida desde una estructura (dimensión espacial) en el devenir (dimensión temporal); esto es, la tendencia hacia el desarrollo, el envejecimiento, la muerte, y entendida como funciones: "(...) el individuo existe en la medida en que plantea y resuelve un problema, pero el problema sólo existe en la medida en que obliga al individuo a reconocer su carácter limitado temporal y espacialmente" (Simondon, 2009, p. 412); es una toma de conciencia de su finitud que le confiere, en una fase más compleja, el carácter de individuo psíquico y lo sitúa en una esfera de problemas que están por encima y por debajo de él mismo. Dicha axiomática deviene en una concepción de lo psíquico que implica, por su propia constitución, la dimensión transindividual; es su respuesta al debate de la época (entre otros, Durkheim, retomado por Mauss, Goldmann, Lévi-Strauss, Piaget, Kurt Lewin y la cibernética de Wiener) en torno al vínculo entre lo individual y lo social (cf. Heredia, 2015).

3 No obstante su proximidad con la fenomenología -por la vía de Merleau-Ponty-, Simondon encuentra limitado el concepto de intersubjetividad, pues, a su juicio, toma los dos polos de la relación como estructuras predeterminadas que se suman o se relacionan. Sobre esta y otras críticas afines, conviene señalar que los conceptos de constitución (Husserl) e institución (Merleau-Ponty) pueden hallar su enlace en una fenomenología de la individuación desde una metafísica que admite el devenir (Vargas, 2014). 
Lo psíquico y lo somático, en vez de dos sustancias separadas, son tipos de funcionamiento que permiten hablar de un "verdadero monismo", que para Simondon es genético, "pues únicamente la génesis asume la unidad que contiene la pluralidad" (2009, p. 404). La percepción (que es interpretación -e invención- de mundo) y la acción (que es posibilidad de incidir en y sobre el mundo) son las características vitales de lo psíquico, gracias a la capacidad de prever (ir hacia el futuro) y de recordar (ir hacia el pasado):

[...] la realidad psicológica es precisamente la instauración de esta reciprocidad a la cual se puede dar el nombre de reflexión. Lo viviente puro integra su experiencia pasada a su conducta presente, pero no puede efectuar la integración inversa, porque no puede poner en juego la reflexión gracias a la cual la conducta presente, ya imaginada en sus resultados y analizada en su estructura, es puesta al mismo nivel ontológico que la conducta pasada. [...] La posibilidad de prever y la de recordar convergen porque son de igual naturaleza y poseen una función única: realizar la reciprocidad entre el orden de lo simultáneo y el orden de lo sucesivo. (Simondon, 2009, pp. 411-412).

Categorías como "individuo psíquico" o "ser psicológico", que remiten a un "ser que se representa su acción a través del mundo como elemento y dimensión del mundo" (Simondon, 2009, p. 33), implican modificar lo que se entiende tradicionalmente por sujeto y por objeto, como otra de las consecuencias de tal axiomática: el conocimiento es "relación entre dos relaciones una de las cuales está en el dominio del objeto y la otra en el dominio del sujeto" (Simondon, 2009, p. 116). De igual modo, se cuestionan las teorías clásicas de la información (incluso, la cibernética), para proponer el énfasis en el receptor, quien se individúa en el proceso, dado que siempre hay grados de indeterminación y la interpretación sucede a la manera de una invención, algo que no estaba antes y deviene afectando el sistema (cf. Blanco \& Rodríguez, 2015; Carrozzini, 2015). El conocer como individuación (del mundo y del sujeto) no puede pensarse sin lo preindividual como motor de un proceso que comienza en la sensación y desemboca en la ciencia, a medida que se estabiliza y se somete a prueba. El autor evita por esta vía las consecuencias de un pensamiento que no ponga en el centro el componente aleatorio, azaroso o contingente de la interacción, dado que es allí donde se da el potencial para nuevas individuaciones.

Pero, ¿quién es el sujeto que conoce? ¿Es el mismo individuo? ¿Queda un concepto subsumido en otro? Resulta por lo menos sugerente concebir la percepción como la invención de una forma e insistir en que el mismo conocimiento es individuación del mundo, de sí mismo, de los otros, con los otros, en una dimensión transindividual. 


\section{Dimensión transindividual: entre axiomática y humanismo}

Para Simondon (2009), "hay en el hombre una necesidad de individuar los objetos, que es uno de los aspectos de la necesidad de reconocerse y de encontrarse en las cosas, de encontrarse allí como ser que tiene una identidad definida, estabilizada por un rol y una actividad" (p. 80). Esta tendencia a conocer el mundo externo, los objetos, es una individuación del conocimiento, que es siempre relación (no preexistencia de los términos). Es más que objeto y sujeto, más que simple adaptación: hay mundo, hay relación en la que se desenvuelve una continua y amplificante resolución de problemas. El medio no está por fuera del individuo como algo acabado o plenamente objetivo: lo sensorial y lo perceptivo esperan por la acción para que el medio como tal se torne significativo, se complete como unidad (Simondon, 2009). De este hecho se deriva la crítica -del mismo orden que la separación entre alma y cuerpo- a la diferencia que suele establecerse entre sensación (más sensorial o somática) y percepción (psíquica, en la medida en que interpreta datos de la sensación). La percepción permite la integración del sistema que es el mundo y el sujeto. El sujeto es individuo más preindividual; es decir, lo que ha logrado individuarse, estabilizarse transitoriamente, conservando siempre un resto que es potencial: "es apenas como información que el ser sujeto puede sobrevivirse en lo colectivo generalizado [...]. Es a través de la naturaleza asociada que existe el contacto con el ser. Ese contacto es información" (Simondon, 2009, p. 464). Lo indeterminado opera siempre en el sujeto, y es lo colectivo lo que permite enlazar en el presente el remanente (preindividual) en cada uno: lo psíquico es expansión de lo viviente, es "una relación de participación que vuelve a ligar cada ser psíquico con los demás seres psíquicos; el psiquismo es lo transindividual naciente" (Simondon, 2009, p. 244), es lo que permite compatibilizar o ajustar la heterogeneidad entre el orden de lo perceptivo y lo afectivo-emotivo.

El individuo psíquico corre el riesgo de sustancializarse en lo que Simondon denomina "doctrinas filosóficas corrientes", pues tiende a reducirse a uno de sus términos lo que es una relación: el pensamiento mismo tiende a sustancializar al sujeto, pero no es más que una reducción, operación de una función, "un cierto modo de individuación secundaria [...] [que] no es necesariamente capaz de pensar el ser en su totalidad; es segundo respecto a la condición de existencia del sujeto" (Simondon, 2009, p. 478).

¿Cuál es el ser en su totalidad? En realidad, el sujeto es solo una dimensión de la individuación, no es el sujeto anhelado que tiene supremacía sobre sí, autocontrol y dominio aislado de un entorno: "el futuro del sujeto es el pasado de la sociedad" (Guchet y Hayward, 2012, p. 86). 
En su devenir hay relaciones, correlaciones, relación de relaciones, en las que el otro es siempre condición de posibilidad para la acción, desde lo que percibe, desea, siente y propone; estar con otros modula la supuesta autonomía del sujeto y se torna en interdependencia.

[...] la elección supone individuación de una parte de la naturaleza no individuada, [...] es descubrimiento e institución de lo colectivo; posee valor autoconstitutivo; hacen falta varias masas de naturaleza preindividual para que la elección se lleve a cabo; la elección no es acto del sujeto solamente; es estructuración dentro del sujeto con otros sujetos $[\ldots]$.

Es por tanto el sujeto, más que el individuo, el que está implicado en la elección; la elección se hace al nivel de los sujetos, y arrastra a los individuos constituidos hacia lo colectivo. La elección es así advenimiento de ser. No es simple relación. (Simondon, 2009, p. 461).

Desde este planteamiento, diferencia lo interindividual de lo transindividual, para señalar que el primero (que denomina out-group, siguiendo la tradición de la psicología de grupos norteamericana) remite a coordenadas de tiempo y espacio, a interacción que no necesariamente convoca la transformación de quienes participan en la acción, como sí sucede en el in group, o dimensión transindividual. Si bien lo interindividual convoca el "descentramiento" del sujeto por la presencia del otro, puede sostenerse sin que medie o se genere la reflexividad cuando acontecen la significación y la acción compartidas. Es esta una implicación ética derivada de la tesis que una y otra vez sostiene el autor: "el psiquismo es vía transitoria hacia lo transindividual"; en otras palabras: "A lo colectivo tomado como axiomática que resuelve la problemática psíquica le corresponde la noción de transindividual" (Simondon, 2009, p. 36). Es el modo de hacer compatible lo individual y lo social, en medio de exigencias -roles, demandas, imágenes, valores y normas-, que requieren, a su vez, un grado de acoplamiento, pero no en pasividad o en mera repetición, pues la fuerza de la vida consiste en inventar nuevas normas en resonancia consigo mismo y con el entorno: "La única vía de resolución es el descubrimiento por parte del sujeto de las significaciones gracias a las cuales lo colectivo y lo individual pueden estar en acuerdo y desarrollarse de manera sinérgica" (Simondon, 2009, p. 460).

Esta dimensión transindividual implica una red afectivo-emotiva, es energética que conforma lo psicosocial; es también la red de individuos y objetos técnicos, mundo reticular de significaciones "articulado por singularidades discontinuas que operan como símbolos y da sentido a las prácticas" (Heredia, 2015, p. 459); esto es, mediado por significaciones, sin las cuales no podrían darse el enlace y la resonancia que disponen a la individuación de quienes participan del entorno, del sistema. Se entiende 
así el vínculo constante entre lo transindividual y la dimensión técnica; los objetos técnicos y la memoria social se ligan de manera indisoluble ${ }^{4}$.

La técnica, en un sentido directo, es también el propio cuerpo, la mano, el lenguaje, la cultura en general, entendida como "manejo de lo humano"; también lo es cuando está mediada por objetos, por herramientas y concretizaciones que resuelven problemas más allá de la utilidad, el uso, la venalidad (Simondon, 2014). Es lo transindividual como tecnicidad: invención, saber acumulado, expresión de lo psíquico vivo.

Con la idea de un ecumenismo de diversos modos de pensamiento, Simondon encuentra en la filosofía -más bien, en el pensamiento filosófico- la posibilidad de integrar lo técnico -primeras objetivaciones-y lo religioso -primeras subjetivaciones-, que luego derivan en pensamiento social y político; lo ético y lo científico; lo teórico y lo práctico, desde la autoconsciencia y la capacidad reflexiva, capaz de ir hacia la génesis, hacia el origen de los objetos técnicos y de la tecnicidad que portan.

La apertura es la principal característica que Simondon atribuye a la tecnicidad, la posibilidad de disponer de los potenciales humanos en las diferentes obras humanas para que, efectivamente, se dé una resolución de problemas en nuevos entornos y situaciones. El pluralismo es otra manera de nombrar la disposición a incluir modos de pensamientos tendientes a una unidad; cuando afirma que es el sujeto quien inventa (más que el individuo), quiere señalar que, más allá de la esfera de cada uno, cuando se concretiza una idea, esta es de todos, como saber de la humanidad.

Su interés de integrar y universalizar la relación entre cultura y técnica, y, a su vez, entre lo sagrado y la tecnicidad-que tienen el mismo origen, según su hipótesis sobre los modos de pensamiento- es un camino de desmitificación (Bardin, 2015, 2013), desde el cual se opone al delirio tecnocrático y al mito tecnófobo. Se reduce la brecha entre los sistemas técnicos y los sistemas sociales mediante la tecnicidad, desde una propuesta que no es solo ética: es político-pedagógica: "Un tal aprendizaje de la tecnicidad aseguraría al individuo y a los grupos un campo más vasto cognitivo y axiológico. [...]. La tecnicidad es una educadora de gran fuerza en materia de planificación, de reticulación funcional de un medio" (Simondon, 2014, pp. 327-328).

Toma la idea de un órgano que en su normatividad intrínseca opera en el cuerpo humano como una resolución funcional; del mismo modo, un objeto técnico se incorpora a la cultura y conserva no solo una información que le ha dado origen, sino también, una dimensión espacial, temporal, histórica. Esta es su normatividad (esquemas perceptivos, operatorios,

4 Se encuentra aquí un enlace entre las dos obras principales del autor, defendidas en 1958 como tesis principal y secundaria, respectivamente (La individuación a la luz de las nociones de forma y de información -ILFI-y El modo de existencia de los objetos técnicos -MEOT-), influenciado en este punto por la noción de cuerpo y de materialidad de Bergson, por la concepción de normalidad de Canguilhem y por la antropología de Leroi-Gourhan (cf. Bardin, 2015). 
soportes de la acción), cuyo trasfondo es una normatividad biológica y cultural: "'La evolución técnica' es crucial para el progreso precisamente porque proporciona la emergencia de un medio técnico que funciona de acuerdo con un régimen de intercambio de información que retroactúa sobre la 'fase' biológica siempre presente en los grupos sociales" (Bardin, 2015, p. 207).

Se trata de una red que se va conformando con su propia normatividad, pero, en tanto opera siempre lo indeterminado, en ella se generan variaciones que podrán ser solo momentáneas, o bien, introducir nuevas formas de organización que logren permanecer e integrarse dentro la normatividad anterior o como emergencia de una nueva. No hay un punto determinado como finalidad, pero sí tendencias, de acuerdo con la información que ha logrado configurarse, organizarse: no es viable cualquier forma u organización; esa es, justamente, su normatividad. La evolución hace referencia a opciones posibles, probables, que, debido a lo aleatorio, no están garantizadas. Se modera así el concepto de progreso, aunque no se plantea una ausencia de tendencias, fines o normas.

[...] no se construye una red por sí mismo: sólo se puede conectar con la red, adaptarse a ella, participar de ella; [...] de allí proviene una forma de participación en el mundo natural y en el mundo humano que otorga una normatividad colectiva incoercible para la actividad técnica; [...] una solidaridad extremadamente concreta y actual, existente instante a instante por el juego de condicionamientos múltiples; a través de las redes técnicas, el mundo humano adquiere un [...] grado de resonancia interna [...]; cuanto más grande sea la resonancia interna de la actividad humana a través de las realidades técnicas, más poder normativo adoptarán [...]. (Simondon, 2007, pp. 237-238).

La técnica convoca la resolución de problemas asociados a necesidades vitales del ser humano, lo cual implica disponer de "[...] condiciones de posibilidad de una inserción eficiente de la tecnología en el medio social de los grupos" (Bardin, 2015, p. 201). Se trata de una transformación activa del entorno, que no se restringe a la utilidad, la venalidad, la obsolescencia o el mero consumo. Mientras más apertura, más opciones de progreso, porque se pueden dar nuevas formas de funcionamiento. Cuanta más integración exista entre los elementos de la red-dentro de cada individuo y en el sistema-, mayores son la resonancia interna y la capacidad de devenir desde nuevos potenciales (cf. Simondon, 2012, 2014).

\section{Un humanismo "renovado"}

La dimensión ontológica y la concepción de sujeto y de conocimiento que subyacen en la perspectiva simondoniana tienen consecuencias no solo epistemológicas, sino también, éticas y políticas: constituyen una forma

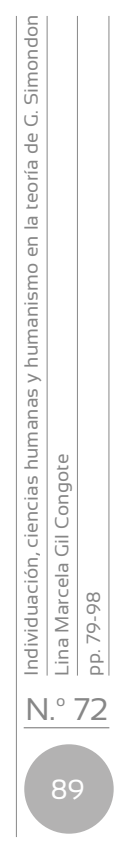


particular de aprender y producir conocimientos, así como una manera de ver y estar en el mundo, donde se consideran los efectos de las acciones y se incluyen los deseos, las necesidades y las particularidades de los otros, en un intento por conformar una red -un "nosotros"-. Si bien se basa en una perspectiva operacional, encuentra en la ética una expresión de formalización de lo que no es operativo: la dimensión afectiva y emotiva, que hacen del ser humano una conjunción psicosomática que encuentra en lo transindividual la posibilidad de desplegar un mundo simbólico que trasciende el ámbito biológico integrándolo en nuevas experiencias y problemáticas.

Su propuesta ética consiste en un optimun entre lo optativo y lo que obliga, en medio de la pluralidad de valores y normas incorporadas en interdependencia, que tiene como norte favorecer una continua individuación en las diversas relaciones del hombre con el mundo: entre el hombre y los objetos técnicos como creación mediada por la cultura, entre los hombres orientados a desplegar potenciales comunes en su dimensión transindividual, espiritual, y entre ellos y la naturaleza, en sus manifestaciones física y vital.

Su humanismo se opone a la sustancialización del ser y opta por el devenir; remite a una búsqueda, a un camino, y no a algo concluido, pero tampoco es una indiferencia de fines o un relativismo, pues el criterio de lo transindividual muestra que no todas las vías apuntan a una realización de sí y de otros en un entorno cultural y técnico.

Para Simondon, cada época tiene sus preocupaciones y orienta sus ideales conforme a los problemas que le asisten y las condiciones del entorno disponibles. En el siglo xx surge la pregunta por los poderes que regulan el mundo y vuelven al ser humano una máquina sin consciencia de lo que le es propio: "Todo enciclopedismo es un humanismo, si se entiende por humanismo la voluntad de llevar a un estatuto de libertad lo que fue alienado del ser humano, para que nada humano sea extraño al hombre" (Simondon, 2007, pp. 120-121). No hay de antemano un humanismo ni los fines están señalados: hay que declararlos, proponerlos como punto de partida para que tomen su fuerza autoconstitutiva.

La normatividad de la técnica no está aislada: es también producto de la invención humana, y la manera como conduzca sus producciones, sus materializaciones, es parte de su destino. Cuestiona lo que denomina un "humanismo fácil" (Bardin, 2013; Barthélémy, 2013, 2014), que pretende rechazar la técnica por ser alienante, sin tomar en cuenta el lugar constitutivo de humanidad que desempeña. Ni tecnofobia ni tecnofilia: cultura técnica; un camino posibilitador de trascendencia en el sentido del devenir transindividual. El sujeto no es lo opuesto a la materia, concebida pasivamente; la materia es potencial para la individuación, para 
la transformación del entorno desde lo intrínseco humano: conjunción de cuerpo, mente y acción. De ahí que entienda la enciclopedia como un "sistema de la actividad [humana], de la producción, [que] modifica el equilibrio social. Es técnico quien prefiere el conocimiento de una operación humana en lugar del conocimiento de una estructura objetiva" (Simondon, 2014b, p. 229).

El humanismo renovado -como lo llama Barthélémy (2014) - consiste en vincular los procesos psicológicos en un entorno que es técnico y tecnológico, constituido por redes de información, más que en cualquier otra época de la humanidad. El potencial preindividual, sin el que no acontece la vida, impide sustancializar o mitificar una idea única de ser humano, pero tampoco se cae en el relativismo, porque se antepone la actitud reflexiva ante las concretizaciones de objetos en su pluralidad (pensamiento técnico), de la mano de la magia, el mito, tendiente a la universalidad y la totalidad (pensamiento religioso), la regulación en los grupos y las sociedades ante problemas actuales, orientados al futuro (pensamiento social y político) y la incorporación de teorías explicativas (pensamiento científico), así como de la invención de nuevas normas, acordes con el individuo y con el entorno (pensamiento ético), desde las cuales el hombre logra ser más consciente de sus determinaciones, siempre presentes, y de su libertad y su responsabilidad. Denomina ecumenismo a esta convergencia de modos de pensamiento, que encuentra en el pensamiento filosófico el punto de anclaje entre el pensamiento ético y el científico:

[...] sólo el pensamiento filosófico [...] la reflexividad del pensamiento es la forma consciente de la resonancia interna del conjunto formado por el hombre y la concretización objetiva; es este pensamiento el que asegura la continuidad entre las fases sucesivas del progreso, y solo él puede mantener la preocupación de totalidad, y hacer de esta manera que el descentramiento [décentration] del hombre, paralelo a la alienación de la concretización objetiva, no se efectúe. (Simondon, 2014c, p. 278).

Propone la figura del psicólogo de las máquinas, o mecanólogo, quien, sin dejarse llevar de los afanes de la productividad, genere formas de representación del objeto técnico, de la mano de otros agentes culturales, que le impidan al hombre quedarse en posición servil frente a la máquina, y pueda, al contrario, constituir finalidades como mediador consciente y responsable del devenir del objeto técnico en la cultura (2007, pp. 164-165). "La sociedad humana, al conocer sus propios mecanismos teleológicos, resulta del pensamiento humano consciente [...]; es un producto del esfuerzo humano organizador y crea la adecuación entre el hecho de estar situado y el hecho de situarse" (p. 123). De este orden es también lo que denomina individuo puro: 
[...] (una categoría que puede conservar la herencia del héroe de Bergson, según Bardin, 2015), pero, más que estar encarnado en un sujeto particular, es una función de mediación más amplia y genérica. Hace referencia al médico, al chamán, al verdadero técnico, que posee un poder individual que lleva a su grupo, a su entorno: capta lo profundo desde el exterior, es un puente entre naturaleza y sociedad; más que un miembro de la sociedad, es un punto singular que reúne las dos condiciones del pensamiento reflexivo: la vida orgánica y la vida técnica. Esta forma de pensamiento le permite mediar entre la comunidad y el objeto que muchas veces permanece escondido en su tecnicidad. (Gil, 2016, p. 123).

Su filosofía expresa la confianza en los potenciales humanos, en el despliegue de capacidades individuales y colectivas, bajo criterios de individuación psíquica y colectiva. El lugar otorgado a la capacidad reflexiva (constitutiva del psiquismo), mediante el pensamiento filosófico como expresión por excelencia de integración de modos de pensamiento y posibilidad de religar lo que se ha desunido, permite "(re)constituir el lazo social a la escala de la humanidad entera" (Bardin, 2013a, p. 338). El ser humano tiene la opción de reencantar el mundo sin mitificarlo (tecnofanía), de recurrir a la estética, a la religión como magia que está contenida en la vida, en las creaciones humanas, en el devenir de la tecnicidad como saber acumulado disponible para otros. Se refiere también a una nueva universalidad del espíritu científico, como un camino de mediación y liberación para el hombre, quien no está condenado a una finalidad ulterior, sino que él mismo, de manera reflexiva, instituye sus sentidos (2007, p. 123).

Hay una confianza en que los hombres, o, mejor, la humanidad -solo deja enunciado cómo se lograría uno a uno por la vía de la significaciónlogre unificar tendencias que han sido separadas y conforme una auténtica cultura técnica. Esta fuerza de su teoría leída como humanismo radica en el carácter auto-constitutivo que le concede a la relación individuo-entorno, de manera que disponga de sus potenciales para que, en un mundo en redes como el mundo al cual asistimos hoy, se pueda superar "una cultura del trabajo para inventar nuevos modos de subsistencia que permita a los hombres existir más [davantage]"; esto es, haciendo eco de categorías de Stiegler, sin que la subsistencia anule la existencia (Barthélémy, 2014, p. 138).

\section{Colofón: biopolítica e individuación}

No se halla explícitamente la categoría de biopolítica en Simondon, pero logra anticipar una época que convoca a la lectura posterior de su obra con una perspectiva política (Bardin, 2015; Berardi, 2007; Combes, 1999; Lazzarato \& Negri, 2001, 2006; Virno, 2003, 2005). La individuación también le concierne al individuo técnico; de retorno, es creación humana que se 
va desplegando desde su ser más abstracto, hasta hacerse más concreto (proceso de concretización), deviene sui, y, a su vez, despliega la individuación humana. La inserción de la técnica y la tecnología trae consigo formas de ser, de comportarse, de orientar la acción, lo que el autor llama "esquemas cognitivos y axiológicos". Justamente por ser transindividual, se desenvuelven dentro de un medio asociado (medio tecnogeográfico, dice Simondon), que es devenir del ser humano en y por su cultura.

La individuación psíquica es, por tanto, uno de los modos de individuación, pero no el único; es una forma de superación del antropocentrismo -herencia de la modernidad y del cristianismo-, pero logra preservar la idea de dignidad humana, de potencial, de progreso, de ascender hacia fases transindividuales, espirituales -idea moderna actualizada como individuación-. Si alguna idea ancla o despliega el posthumanismo, esa es la técnica, y es en entrelazamiento entre técnica y ser humano donde aparece la biopolítica. El paso de las sociedades donde sujetos controlan a otros sujetos a sociedades de captura de la subjetividad (Deleuze, 2006; Rodríguez, 2009, 2010) por medios tecnológicos: publicidad, pornografía, mercado, etc. Pero, aún ahí, deviene el ser, la resistencia, la objeción, el valor, la norma, que devuelven sentido de mundo y de vínculo en un entorno tecnologizado, pero no alienado o alienante. Las nuevas formas de subjetivación, de identidad, de nomadismo (cyborg, comunidades LGTBI, inmigrantes, desplazados, reinsertados, excluidos...), son desafíos para la formación y la transmisión de este pensamiento reflexivo que una y otra vez se sitúa en el centro de una propuesta ética, pedagógica y política.

La lectura de la obra de Simondon ha contribuido al debate sobre prácticas de manipulación de la subjetividad, bajo fines meramente productivos o imperativos del capital y del consumo que restringen las posibilidades de colectividad; ha fundamentado propuestas de información de libre acceso en redes, espacios virtuales colaborativos (Hui \& Halpin, 2013; Ilnicki, 2011) en los que se propone pasar de las tecnologías del control a tecnologías del espíritu (spirit), que integren en una política de la existencia, formas de resistencia en un entorno viable para el ser humano y la técnica; en la medida en que es resolución de problemas, fomenta las razones para vivir juntos y cuidar del otro (Stiegler y Rogoff, 2010). La dimensión política no necesariamente remite a un cambio de estructura: más bien, como dice Berardi (2007), es un giro de la mirada, otro modo de ver, un gesto que podrá tomar fuerza y puede amplificarse como acción que hace sentido para uno, para otro, para todos, dentro de un referente común. Lo transindividual es así trascendente en el sentido de convocar la presencia y el encuentro.

La obra de Simondon se puede entender así como la convergencia, vía la axiomática, de unos principios racionales, explicativos del devenir del ser desde paradigmas contemporáneos, y, vía el humanismo, de 
valores y normas individuales y colectivas, los cuales, más que un poder explicativo (como la axiomática), ofrecen un contexto axiológico, ético y político. El autor anticipa modos de ser y de vivir que desafían los límites de su época y convoca nuevas interpretaciones y significados, sin abandonar del todo un contexto o un referente moderno, que puede verse como un saber prudencial, axiológico, praxeológico, en el cual, no obstante, nadie impone un único modo de ser, de pensar, de hacer; es en una red que deviene ${ }^{5}$.

Los principios de esta axiomática para las ciencias humanas, presentes en lo ya expuesto, sugieren en su conjunto la superación del psicologismo y del sociologismo a través del concepto de individuación psíquica y colectiva, lo cual conduce a una posición humanista que se consolida en las características según las cuales opera la dimensión transindividual. A modo de síntesis, se puede decir que individuo y medio son relación, y esta tiene carácter de ser; el individuo es una compatibilización de energía que supera el hilemorfismo materia y forma, ante la cual se propone la energía para conformar una triada. El resto, o preindividual, es remanente que permanece aparejado al sujeto y es el potencial para nuevas individuaciones; estas no acontecen en cualquier sentido o dirección: en un individuo psíquico se disponen a la búsqueda de significaciones compartidas que constituyen la dimensión colectiva (axiomática para lo transindividual), modo de compatibilizar lo afectivo y lo emotivo. Lo interindividual es estadio previo y necesario -si se quiere, de transición- hacia una dimensión que es transindividual, al menos, en dos sentidos: desde lo espiritual, y desde la tecnicidad, pero no en un sentido externo o trascendente, sino como conjunción de esfuerzos en obras que perduran. Por esta última vía, la de la tecnicidad, se desarrolla gran parte de la obra del autor, por lo cual no solo alcanza su reconocimiento como filósofo de la técnica, sino que también puede ser tomado como un humanismo renovado, que algunos ven con reserva por ser aun moderno -incluso, ingenuo- en sus aspiraciones (Bardin, 2015; Barthélémy, 2005, 2010, 2014), pero aquí se presenta como una propuesta poderosa para pensar la formación y los diferentes ámbitos en los que se desenvuelve el sujeto advertido de cualquier tipo de alienación y dispuesto a permanecer como ser individuándose, en proceso, en devenir.

5 De la misma forma como tematiza sus principales conceptos, esta convergencia no es mera suma o relación: es una afectación y una transformación mutua -transductiva y amplificante- de una dimensión a otra. Frente a la separación entre "ciencias de la naturaleza" y "ciencias del espíritu" de Dilthey (1944), cuestionada desde otras posiciones, debido a la escisión entre explicación y comprensión, respectivamente (Husserl, [1911/2008]; Habermas, 1988); Simondon se situaría en una posición integradora al señalar que los principios que subyacen a la organización de la materia y de la vida como energética estructural y estructurante marcan tendencias que se proyectan en la acción, en los modos de resolución de problemas, pues comportan una normativa que es constitutiva del ser. En la dimensión psíquica se expresa también mediante esquemas "cognitivos y axiológicos" que operan en las producciones humanas; especialmente, en la técnica y en la tecnología en su inserción en la cultura. 
Se elige la ruta de lo transindividual como punto de enlace entre las ciencias humanas y el humanismo; en vez de desvincular ambos campos, se halla un núcleo común entre humanismo y posthumanismo, entre ciencias humanas y humanidades. Un sujeto, pero no sustancializado; unos fines, pero no predeterminados, solo convocados para que al ser puestos en marcha tomen fuerza autoconstitutiva como fuente para nuevas individuaciones.

Simondon busca desentrañar la génesis de la vida desde las diferentes fases del ser para comprender los procesos psicológicos y sociales en un entorno técnico y tecnológico. La propuesta de "universalizar" la energética que subyace a todo proceso de individuación (axiomática) se conjuga con una posición humanista que advierte fines, valores y normas encauzadas hacia una cultura técnica. Se derivan así unas ciencias humanas con humanismo, sin cientificismo, con reflexión y crítica, para integrar modos de pensamiento capaces de hacer objeción y límite a las formas que impidan la individuación, vía la imaginación y la invención. En contra, en fin, de la sustancialización y de todo lo que reduzca el ser a una interpretación única.

El entorno de formación será el que favorezca la dimensión transindividual en sus expresiones (afectivo-emotiva, técnica, espiritual) y cree condiciones para devenir uno, singular, diferente $y$, al mismo tiempo, en vínculo con otros, en el reconocimiento de lo común. Una formación para conformar un entorno en que tengan lugar los diferentes modos de existencia, las diversas formas de desenvolvimiento de una singularidad. Hay vacío, resto, soledad, angustia, y al mismo tiempo emotividad y afectividad disponible para entrar en vínculo desde una normatividad propia y del entorno que restringe todo aquello que coarte la posibilidades del ser en su multiplicidad o imponga un camino único y definitivo para todos. Como dice Barthélémy (2014), Simondon es un filósofo que cree en la capacidad reflexiva para captar el devenir; también, para ayudarle al ser en su devenir. En eso consiste la formación. 


\section{Referencias}

Bardin, A. (2013). De l'homme à la matière: pour une "ontologie difficile". Marx avec Simondon. Cahiers Simondon, 5, 25-43.

Bardin, A. (2015). Epistemology and Political Philosophy in Gilbert Simondon. Individuation, Technics, Social Systems. Dordrecht: Springer.

Barthélémy, J-H. (2005). Penser l'individuation: Simondon et la philosophie de la nature, París, Francia: L'Harmattan.

Barthélémy, J. H. (2010). What new humanism today? Cultural Politics, 6 (2), 237-252.

Barthélémy, J. H. (2013). Glossaire Simondon. Les 50 grandes entrées dans I'ouvre. Cahiers Simondon, 5, 105-137.

Barthélémy, J-H. (2014). Simondon. París: Les Belles Lettres.

Berardi, F. (2007). El sabio, el mercader y el guerrero. Del rechazo del trabajo al surgimiento del cognitariado. Madrid: Acuarela \& A. Machado.

Blanco, J. y Rodríguez, P. (2015). Sobre la fuerza y la actualidad de la teoría simondoniana de la información. Amar a las máquinas. Cultura y técnica en Gilbert Simondon (Blanco, J., Rodríguez, P.; Parente, D; Vaccari, A. Comp.). Buenos Aires: Prometeo.

Carrozzini, G. (2015). How to invent a form: An inquiry into Gilbert Simondon's philosophy of perception. En A. Sarti, F. Montanari y F. Galofaro (eds.), Morphogenesis and Individuation (pp. 33-48). Suiza: Springer.

Combes, M. (1999). Simondon. Individu et collectivité: pour une philosophie du transindividuel. París: Presses Universitaires de France. Recuperado de: http://monoskop.org/images/b/bb/Combes_Muriel_ simondon_individu_et_collectivite_Pour_une_philosophie_du_transindividuel.pdf

Deleuze, G. (2005). Gilbert Simondon: El individuo y su génesis físico-biológica. En: La isla desierta y otros textos. Textos y entrevistas (19541974) (pp. 115-120). Valencia: Pre-textos.

Deleuze, G. (2006). Post-scriptum sobre las sociedades de control. Polis: Revista Latinoamericana, 13. Recuperado de http://polis.revues. org/5509

Del Lucchese, F. (2009). Monstrous Individuations: Deleuze, Simondon, and Relational Ontology. Differences, 20(2-5), 179-193. DOI: 10.1215/10407391-2009-008

Dilthey, W. (1944). Introducción a las ciencias del espíritu. México: Fondo de Cultura Económica.

Foucault, M. (1997). Las palabras y las cosas: una arqueología de las ciencias humanas. México: Siglo xxı.

Gil, L. (2016). Psicología, trabajo e individuación. Bogotá: San Pablo. 
Guchet, X. \& Hayward, M. (2012). Technology, Sociology, Humanism: Simondon and the Problem of the Human Sciences. SubStance, 41(3), 76-92.

Habermas, J. (1988). La lógica de las ciencias sociales. Madrid: Tecnos.

Heredia, J. (2015). Lo psicosocial y lo transindividual en Gilbert Simondon. Revista Mexicana de Sociología, 77(3), 437-465. Recuperado de: http://www.scielo.org.mx/scielo.php?script=sci_arttext\&pi$\mathrm{d}=$ S0188-25032015000300004\&lng=es\&tlng=es

Hui, Y. \& Halpin, H. (2013). Collective individuation. The future of the social web. En G. Lovink y M. Rasch (eds.). Unlike as reader. Social media monopolies and their alternative. Amsterdam: Institute of Network Cultures, pp. 103-116. Disponible en: http://dare.uva.nl/ document/2/119288\#page $=106$

Husserl, E. (2008). La crisis de las ciencias europeas y la fenomenología trascendental (J. V. Iribarne, trad.). Buenos Aires: Prometeo.

Iliadis, A. (2013a). Informational Ontology: The Meaning of Gilbert Simondon's Concept of Individuation. Communication+1, 2.

Iliadis, A. (2013b). A New Individuation: Deleuze's Simondon Connection. MediaTropes elournal, 4(1), 83-100.

Ilnicki, R. (2011). Teleindividuation. Lingua ac Communitas, 21, 163-174.

Lazzarato, M. \& Negri, A. (2001). Trabajo inmaterial. Formas de vida y producción de subjetividad. Río de Janeiro: DP\&A Editora. Recuperado de: http://www.rebelion.org/docs/121986.pdf

Lazzarato, M. \& Negri, A. (2006, diciembre). Trabajo inmaterial y subjetividad. Brumaria. Arte, máquinas, trabajo inmaterial, 7, 45-54.

Rodríguez, P. (2009). El renacimiento de la biopolítica. Notas para un balance. Tramas, subjetividad y procesos sociales, 32, 63-98.

Rodríguez, P. (2010). ¿Tiene sentido hablar de poshumanismo? Acerca de la relación entre teoría de la comunicación y biopolítica de la información. Galaxia, 20, 9-12. Recuperado de: http://revistas.pucsp.br/ index.php/galaxia/article/view/4646

Rodríguez, P. (2016). L'information entre Foucault, Deleuze et Simondon. En : Gilbert Simondon ou l'invention du futur. Actes du colloque de Cerisy. Paris: Klincksieck, 217-226

Simondon, G. (2007). El modo de existencia de los objetos técnicos. Buenos Aires: Prometeo Libros.

Simondon, G. (2009). La individuación a la luz de las nociones de forma y de información. Buenos Aires: Ediciones La Cebra y Editorial Cactus.

Simondon, G. (2012). Curso sobre la percepción (1964-1965). Buenos Aires: Cactus. 
Simondon, G. (2013). Imaginación e invención (1965-1966). Buenos Aires: Cactus.

Simondon, G. (2014). Sur la technique 1953-1983. París: PUF.

Simondon, G. (2015a). Forma, información y potenciales. En: La individuación a la luz de las nociones de forma e información. Buenos Aires: Cactus. [Segunda edición corregida y aumentada]

Simondon, G. (2015b). Sur la psychologie (1956-1967), Paris: PUF.

Sloterdijk, P. (2000). Reglas para un parque humano: una respuesta a "Carta sobre el humanismo". Pensamiento de los confines, 8, 9-22.

Stiegler, B. \& Rogoff, I. (2010, marzo). Transindividuation. E-Flux Journal, 14.

Vargas, G. (2014). Individuación y anarquía. Metafísica y fenomenología de la individuación. Bogotá: Aula de Humanidades.

Vargas, G. \& Gil. L. (2015). Excelencia, excedencia e individuación. Revista Colombiana de Educación, 68, 65-90.

Virno, P. (2003). Gramática de la multitud. Para un análisis de las formas de vida contemporáneas. Madrid: Traficantes de Sueños.

Virno, P. (2005). Cuando el verbo se hace carne. Lenguaje y naturaleza humana. Madrid: Traficantes de Sueños. 